\title{
INTRA-SEXUAL SELECTION IN DROSOPHILA
}

\author{
A. J. BATEMAN \\ John Innes Horticultural Institution, Merton
}

Received I3.iii.48

\section{INTRODUCTION}

SINGE Darwin first wrote on the subject in I87I, sexual selection has been generally accepted as one of the basic facts of biology. The evidence in its favour seems, however, to be mainly circumstantial. Its existence has usually been inferred from sex differences depending on what are called secondary sexual characters which are supposed to have arisen as results of that selection. Such an approach has its dangers, and Huxley (1938) has made important criticisms of the original concept of sexual selection. He has shown that a large number of characters which have been attributed to sexual selection are unconnected with competition for mates. This is particularly the case in monogamous birds which offer some of the most striking examples of secondary sexual differences. In the first place monogamy, at least when the sexes are numerically equal, is the mating system least likely to develop sexual selection. In the second place, and more important, observations on bird behaviour have shown that much of the display of birds occurs after pairing, when competition must have ceased. Such sexual differences are concerned, either with inducing the female to copulate, or with maintaining the association of the sexes as long as it is necessary for the rearing of the young.

Huxley therefore introduced the term epigamic to apply to characters which increased the fertility of a given mating and therefore had a selective value for the species as a whole. Epigamic selection includes the major part of what Darwin meant by sexual selection. It also includes selection for characters to which Darwin did not refer, such as the structure of copulatory organs, sex differences in frequency of crossing over, and the XY mechanism. It is only a special case of natural selection as generally understood. What remains of Darwinian sexual selection has been called intra-sexual selection, which denotes that it involves competition between members of one sex for mates. It can only indirectly affect the survival of the species and then is often deleterious (e.g. the cumbersome antlers of the stag). There is not invariably, however, a clear distinction between epigamic and intrasexual selection. In a promiscuous species like Drosophila pairing and copulation are synchronous. Courtship behaviour determines the number of mates and therefore enters into intra-sexual selection. 
Intra-sexual selection has been demonstrated in Drosophila a number of times in the shape of sexual isolation between species, geographic races and mutants. Table I gives some typical examples.

TABLE I

Examples of sexual isolation in Drosophila spp. arranged in descending order of magnitude

\begin{tabular}{|c|c|c|c|c|}
\hline \multicolumn{4}{|l|}{ Isolation between } & Authority \\
\hline $\begin{array}{l}D . \text { pseudoobscura and } D \text {. miranda } \\
D \text {. pseudoobscura strains } A \text { and } B \\
\text { Certain mutants of } D \text {. pseudoobscura } \\
\text { Yellow mutant and wild type of } D \text {. } \\
\text { Geographic races of } D \text {. sturtevanti } \\
\text { Geographic races of } D \text {. melanogaster } \\
\text { Selection lines of } D \text {. melanogaster }\end{array}$ & $\begin{array}{c}\cdot \\
\dot{A} \\
\text { subobscura } \\
\dot{\cdot} \\
\dot{\cdot} \\
\dot{\cdot}\end{array}$ & $\begin{array}{l}\dot{b} \\
\dot{ } \\
\dot{ }\end{array}$ & $\begin{array}{l}\dot{.} \\
\dot{.} \\
\dot{.} \\
\text {. }\end{array}$ & $\begin{array}{l}\text { Dobzhansky and Koller, I } 93^{8} \\
\quad, ", ", \\
\text { Tan, I } 946 \\
\text { Rendel, I } 944 \\
\text { Dobzhansky, I } 944 \\
\text { Mather unpublished } \\
\text { Mather and Harrison, I } 94^{8}\end{array}$ \\
\hline
\end{tabular}

The standard technique is to enclose one kind of male with two kinds of female, one of them the same as the male, and then to observe the relative frequency of insemination of the two kinds of female.

Now it is generally assumed that intra-sexual selection almost invariably involves competition between males, the females exercising choice, and not the reverse. The presence of secondary sex differences does not allow one to decide the issue, since there is no a priori reason for assuming one sex to be primitive and the other derivative. It would be conceivable that both sexes had deviated equally from an unspecialised ancestral type. The assumption that it is the males which are mainly subject to the intra-sexual selection is in fact based mainly on the behaviour of animals. Darwin took it as a matter of general observation that males were eager to pair with any female, whereas the female, though passive, exerted choice. He was at a loss, however, to explain this sex difference, though it is obviously of great importance for an understanding of intra-sexual selection.

Drosophila seems to be no exception to the rule. In the paper cited above, Rendel observed courtship in $D$. subobscura. It is the male which makes the advances to any female and often even to other males, and it is the female which accepts or rejects the advances. This observation was supported by the peculiar effect of the mutant vellow as shown in reciprocal matings :-

$$
\begin{aligned}
& \text { yellow 우우 }+\delta^{\lambda} \delta^{*} \text { Ioo per cent. inseminated }
\end{aligned}
$$

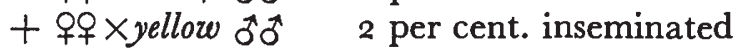

The males courted equally vigorously in both matings. Thus wild type females found yellow males objectionable, but wild type males failed to discriminate between yellow and wild type females. Females differed genetically in their discrimination against yellow males and it was possible by selection to obtain wild type strains which gave 
fully effective matings with yellow males. A similar sex difference in effect of yellow on mating behaviour has been observed in $D$. pseudoobscura by Tan (I946). Other mutants affecting mating behaviour in this species were aristapedia, which did not affect males but reduced the mating capacity of the females (possibly by interfering with their ability to detect courting males); and the Bare Curly combination, which again did not affect males but enhanced the mating capacity of females. (Perhaps Curly females were unable to interpose their wings between their abdomina and approaching males.) The actions of all these mutants stress that it is the female which exercises the choice.

Nevertheless there is some evidence of discrimination by males. Stalker (I942) using the two subspecies virilis and americana of $D$. virilis found that the males of one subspecies ignored females of the other and were actually courted by them. It is to be expected of course, that if males are enclosed with sufficiently unrelated females they will show discrimination. Stalker's case is remarkable, however, in that the males showed more discrimination than the females of the other subspecies. Dobzhansky and Koller (1938) carried out a test for discrimination by males. Males of $D$. pseudoobscura which had been kept with their own females for five days and males which had been kept isolated from females for the same time were introduced to mixtures of $D$. pseudoobscura and $D$. miranda females. In both cases all the $D$. pseudoobscura females were inseminated, but the previously isolated males inseminated the higher proportion of $D$. miranda females. This was interpreted to mean that the isolated males had greater sexual appetites and were therefore less discriminating. A second possibility, which again involves the assumed capacity of males to discriminate, would be that males accustomed to mate with $D$. pseudoobscura females would show a greater preference for the same type when given choice than males with no previous experience. A third possible explanation not involving male discrimination was admitted. This was that the males which had been isolated might have inseminated the females of both species more frequently, but, as multiple inseminations could not be detected, the additional matings would only be noticed in the $D$. miranda females most of which remained unmated.

Dobzhansky has been most careful throughout his papers not to commit himself on the matter of which sex is exercising the discrimination. Tan ( 1946 ), on the other hand, interprets his data by assuming without evidence that it is the males which discriminate. In the now standard experiments on discrimination one kind of male is enclosed with two kinds of female. (As the observations are made on the ventral tubes of the females this arrangement is unavoidable until a new technique is perfected.) It is easy to fall into the error of assuming that it is the male which "chooses" between two kinds of female : the results could equally well be interpreted on the assumption that the two kinds of females discriminate with specific strengths against the same males. 
Thus, so far as the evidence from observations on behaviour goes, it would appear that though discrimination is sometimes found in males, it is almost confined to the females. In other words intra-sexual selection is predominantly intra-masculine. Widespread though this sex difference in discrimination is generally understood to be, it does not appear to be a primary feature of sexual reproduction : it must be supposed to have evolved as a secondary sexual difference. In so far as the so-called secondary sex characters have arisen through the action of sexual discrimination, which is itself only secondary, they must be regarded as strictly tertiary.

The mating system of a species was considered by Darwin to be an important element in determining sexual selection. The only mating system in which intra-sexual selection is ineffective is strict monogamy with numerical equality of the sexes. (Monogamy implies that the mating group in any one breeding season is a single pair. It is immaterial from the point of view of sexual selection whether or not the same pair is mated for life.) All other systems, polygyny, polyandry, promiscuity, and numerical inequality of the sexes alone, will allow intra-sexual selection.

Darwin supposed that intra-masculine selection predominated because it was produced by the commonest mating systems. These were, monogamy combined with an excess of males, and polygyny (he used the ambiguous term " polygamy"). But why, then, should not the two corresponding systems inducive of intra-feminine selection, namely monogamy with excess of females and polyandry, be equally common? It must be that only those mating systems compatible with intra-masculine selection have arisen. Consequently one must assume that intra-masculine selection determines the mating system and not, as Darwin supposed, that the mating system determines intra-masculine selection.

It is thus desirable to search for a fundamental cause of intramasculine selection, independent of mating system and probably inherent in the mechanics of sexual reproduction. This same cause should show us why it is a general law that the male is eager for any female, without discrimination, whereas the female chooses the male. The experiments to be described concern a species, Drosophila melanogaster, in which the sexes are numerically equal and mating is promiscuous. Though discrimination between races has been demonstrated (Mather and Harrison unpub.) it is less marked than in some of the species referred to above. This species would not, therefore, appear at first sight to be particularly favourable material for demonstrating intra-sexual selection. Even in this species, however, as the results will show, sexual selection, if not confined to the males, preponderates in them. The results also indicate the cause of this sex difference in intensity of selection. 


\section{METHODS}

The experiments use in a novel way the relation between selection and fertility. The fertility of an individual is here taken to mean its actual contribution to the next generation, rather than, as is sometimes meant, its potential contribution. The basic assumption made is that for a given genetic variation the variation in fertility increases with selection. Variance in fertility is in fact a measure of the intensity of selection.

The paradoxical relation between selection and fertility may be considered further. On the one hand selection, by eliminating certain genotypes, reduces the genetic variation of a population (including genetic variation in fertility). On the other hand selection causes an immediate increase in the phenotypic variation in fertility. As selection proceeds and genetic uniformity increases, the phenotypic variation in fertility will of course gradually decrease again. When selection is relaxed the immediate result will be a rapid further decrease in phenotypic variation in fertility, whereas genetic variation will only increase gradually as a result of mutation and recombination.

To return to the main argument, a sex difference in variance of fertility is therefore a measure of the sex difference in intensity of selection, which indicates that intra-sexual selection is greater in one sex than the other.

The fertility of individual flies of both sexes was measured by means of dominant marker genes. Several flies of each sex were mated together in one bottle, each fly carrying a different dominant marker gene. In this way, assuming the complete viability of all the marker genes, half the progeny of each fly could be identified. Any effects of differential viability of the marker genes can be isolated and removed in the experiments involving reciprocal matings. The identifiable progeny were used to estimate the variances in fertility of their parents.

Moreover one quarter of the progeny of each fly will carry two marker genes, one from each parent. In this way it is possible to determine which matings have taken place, and in how many inseminations each fly has participated. The number of inseminations identified should, however, be regarded as a minimum, for two reasons : the possibility that some matings might be ineffective, and the inability to distinguish single and multiple inseminations involving the same pair of flies.

First, it may not be possible to identify all the males by which the female has been inseminated. According to a number of authors (Nachtsheim, I927 ; Dubinin, I928 ; Kaufmann and Demerec, 1942), when a female is inseminated twice, the second batch of sperm supersedes the first which only reappears in the progeny when the second batch has been consumed. Thus it might be possible when two matings occurred in quick succession for no progeny from the 
first mating to appear. Lobashov (1939) on the other hand claimed to get complete mixture of sperm. Some of the data enable one to assess the likelihood that replacement of one kind of sperm by another might interfere with the results. In series 5 (see table 3) the mated flies were transferred each day for 4 days to new bottles. In this way it was possible to observe whether a female producing progeny derived from the sperm of two males utilised the two batches of sperm separately or together.

\begin{tabular}{|l|c|c|c|c|c|}
\hline Kind of sperm . & Ist & \multicolumn{4}{|c|}{ 2nd } \\
\hline Day when first used . & I st & Ist & 2nd & 3rd & 4th \\
\hline \hline Mixing of sperm . & I I & 4 & 6 & I & $\ldots$ \\
\hline No mixing & 3 & $\ldots$ & I & I & I \\
\hline
\end{tabular}

Evidently if the second insemination occurs soon after the first there is complete mixing of sperm, but as the interval of time between inseminations increases the second insemination becomes more likely to supersede the first. A mating would escape detection only when a second occurred a short time after the first and there was no mixing of sperm. The evidence is that this is rare.

An examination of the papers referred to above supports this conclusion. Kaufmann and Demerec introduced the second male 3 days after the first and Nachtsheim allowed 8 days to elapse before allowing a second mating. If Lobashov (whose original paper is not available) used a shorter interval the contradictions between their results would be resolved.

The second source of error is that one cannot measure directly the number of inseminations, but only the number of mates. The number of mates need not of course equal the number of inseminations, though it can never be greater. If, however, mating is unassortative and there is no tendency to monogamy, the discrepancy between the number of mates and the number of inseminations will be slight, unless the number of mates per fly is large. The average number of mates per fly varied from I to I 9 , whereas the maximum possible number was in most cases 3, sometimes 5. The error introduced by regarding the number of mates per fly as the number of inseminations will not, therefore, be serious.

The marker genes used in the experiment were extracted from various laboratory stocks. They are listed and described briefly in table 2. Some $\left(P m, C y, C y L^{4}, S b, M e ́\right)$ marked inversions. The rest $(B, B l, H, M c)$ were unaccompanied by inversions. The extracted mutants were at first kept in mass cultures by mating marked females to wild type males from the same stock. These stocks would 
contain a large amount of internal genetic variability. As it was desired to reduce to a minimum the genetic causes of variability in fertility, all these stocks were later crossed to Or+inbred, a stock which had been maintained by brother-sister mating for over 200 generations. They were then backcrossed to $\mathrm{Or}+$ for several generations using females carrying the marker genes, during which time the genetic variability within stocks must have become very low and the stocks would differ from one another mainly by the marker genes and the

TABLE 2

Description of the dominant marker genes used in the experiments

\begin{tabular}{|c|c|c|c|}
\hline Chromosome & Symbol & Name & Main effect \\
\hline III & $\begin{array}{l}\text { Hw } \\
B \\
P m \\
C y \\
C y L^{4} \\
B l \\
S b \\
M e \\
H \\
M c\end{array}$ & $\begin{array}{l}\text { Hairy-wing } \\
\text { Bar } \\
\text { Plum } \\
\text { Curly } \\
\text { Curly-Lobe } \\
\text { Bristle } \\
\text { Stubble } \\
\text { Moire } \\
\text { Hairless }\end{array}$ & $\begin{array}{l}\text { Extra long bristles on wing veins. Homo- } \\
\text { zygote viable and more extreme. } \\
\text { Reduction of size of eye which becomes a } \\
\text { narrow kidney shape. Homozygote fully } \\
\text { viable and more extreme. } \\
\text { Eye colour brown : slight darkening of } \\
\text { body colour. Homozygote lethal. } \\
\text { Wings curled upwards. Homozygote lethal. } \\
C y \text { with, in addition, eye reduced in size } \\
\text { and with a nick in the ventral edge. } \\
\text { All bristles shortened and thickened. } \\
\text { Homozygote lethal. } \\
\text { Same as Bl. } S b+B l \text { more extreme than } \\
\text { either. } \\
\text { Eyes paler than wild type with shimmering } \\
\text { appearance of shot silk. Body colour } \\
\text { paler. Homozygote lethal. } \\
\text { Hairs removed from various parts of the } \\
\text { body, particularly the post verticals at } \\
\text { back of head. Homozygote lethal. } \\
\text { Eyes reduced or absent. Homozygote } \\
\text { viable. }\end{array}$ \\
\hline
\end{tabular}

parts of the chromosomes closely linked with them. As a result of this backcrossing the fertility fell sharply and the flies were in effect monogamous. The males may in fact have been incapable of more than one fertile copulation. This was useless for the purposes of the experiment, so fertility and mating frequency were restored but uniformity retained by crossing these lines to another inbred line, the Samarkand +inbred. The parents for the final series of experimental matings were then $F_{1} s$ between the two inbred stocks.

Full identification of flies carrying two marker genes was not always possible because of interaction between them. In the earlier matings when five flies of each sex were used, the females carried $H w, P m, S b, M e ́$ and $H$ while the males carried $B, C y, C y L^{4}, B l$ and $M c$. The former group of genes was called $C$ and the latter $D . B l$ and $S b$ were indistinguishable from one another unless they were in combination with another marker. If a fly which might be $B l$ or $S b$ also carried a marker from group $D$ the first mutant must have been from group $C$ (i.e. $S b$ ). When $B l$ and $S b$ occurred together a distinct 
phenotype developed more extreme than either. The fertility of $B l$ and $S b$ flies was calculated by assuming that the ratio of simple $B l$ to simple $S b$ was the same as the ratio of combined $B l$ to combined $S b$ and dividing the unclassifiable flies between $B l$ and $S b$ accordingly.

Another complication arose through the interaction of $P m$ and $M \dot{e}$ with $M c$. It is impossible completely to score $M c$ flies for eye colour, as some of them are eyeless. This would have the effect of reducing the apparent fertility of $P m$ and $M e ́$ genotypes, but only when the fertility of a mating between $M c$ and $P m$ or $M \dot{e}$ was very low could the mating be overlooked as a result of this interaction.

In later experiments the number of flies of each sex was reduced to three, the markers being $P m, H$ and $S b$ (group $A$ ) and $C y L^{4}, C y$ and $M c$ (group $B$ ). To minimise error variation in any series of matings all the flies of one sex were kept in the same sexing tube

TABLE 3

The distinctive features of the various series of matings

\begin{tabular}{|c|c|c|c|c|c|c|}
\hline 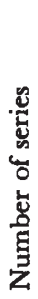 & $9 \times 0$ & 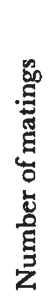 & 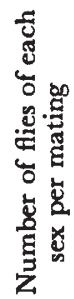 & 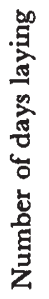 & Age relationship & Pedigree of parents \\
\hline $\mathbf{I}$ & $\mathrm{G} \times \mathrm{D}$ & 5 & 5 & 3 & $\mathrm{O}, \mathrm{M}$ and $\mathrm{N}$ mixed at & Mass cultures \\
\hline 2 & $\mathrm{G} \times \mathrm{D}$ & 9 & 5 & 3 & $\begin{array}{l}3 \text { bottles each of } \mathrm{O}, \mathrm{M} \\
\text { and } \mathrm{N}\end{array}$ & Mass cultures \\
\hline 3 & $\mathbf{B} \times \mathbf{A}$ & 9 & 3 & 4 & $\begin{array}{l}\text { All } 9 \text { combinations of } \\
\mathrm{O}, \mathrm{M} \text { and } \mathrm{N} \text {. Flies } \\
\text { of same sex in a } \\
\text { bottle all of same age }\end{array}$ & Mass cultures \\
\hline 4 & $\begin{array}{l}\mathrm{A} \times \mathrm{B} \\
\mathrm{B} \times \mathrm{A}\end{array}$ & 8 & $\begin{array}{l}3 \\
3\end{array}$ & $\begin{array}{l}3 \\
3\end{array}$ & $\begin{array}{l}2 \text { bottles of } \mathrm{O}, 3 \text { of } \mathrm{M} \\
\text { and } \mathrm{N} \text {. } \\
3 \text { bottles of } \mathrm{O}, \mathrm{M} \text { and } \\
\mathrm{N}\end{array}$ & Crossed to $O r+$ for 3 generations \\
\hline 5 & $\begin{array}{l}\mathbf{A} \times \mathbf{B} \\
\mathbf{B} \times \mathbf{A}\end{array}$ & $\begin{array}{l}4 \\
4\end{array}$ & $\begin{array}{l}3 \\
3\end{array}$ & $\begin{array}{l}4 * \\
4\end{array}$ & All $\mathbf{M}$ & $\begin{array}{c}\mathrm{F}_{1} \text { between } S k d+\text { and backcross to } \\
\text { Or+ after } 6 \text { generations }\end{array}$ \\
\hline 6 & $\begin{array}{l}\mathbf{A} \times \mathbf{B} \\
\mathbf{B} \times \mathbf{A}\end{array}$ & $\begin{array}{l}8 \\
8\end{array}$ & $\begin{array}{l}3 \\
3\end{array}$ & $\begin{array}{l}3 \\
3\end{array}$ & All $\mathrm{M}$ & $\begin{array}{c}\mathrm{F}_{1} \text { between } S k d+\text { and backcross to } \\
\text { Or+ after I } 5 \text { generations }\end{array}$ \\
\hline
\end{tabular}

$S k d+=$ Inbred stock from Samarkand wild type.

Or $+=$ Inbred stock from Oregon wild type.

$\mathrm{A}=P m, H$ and $S b$.

$\mathrm{B}=C y L, C y$ and $M c$.

$\mathrm{C}=H w, P m, S b, H$ and $M \ell$.

$\mathrm{D}=B, C y, C y L, B l$ and $M c$.

$\mathrm{O}=$ Flies mated at 6 days old.

$\mathrm{M}=$ Flies mated at 3 days old.

$\mathrm{N}=$ Flies mated at I day old.

* Flies transferred to new bottle every day.

until the day before mating. They were then grouped into sets of three or five and given a day to recover from the effects of ether before both sexes were introduced into the bottles. Copulating pairs 
were frequently observed within a few minutes of introducing the sexes. The flies were allowed to lay 3 or 4 days. In one instance (series 5 of table 3) the flies were transferred to fresh bottles every day for 4 days.

The age of the flies was variable. There were three age groups according to the ages at which they were allowed to mate : 1,3 and 6 days old. The distinctive features of the six series of matings are shown in table 3. An example of the way in which each mating was analysed is shown in table 4. In all, 220 flies of each sex were used as parents in the experiments.

TABLE 4

Sample result of one mating. From series $6 \mathrm{~B} \times \mathrm{A}$, sixth bottle $(C y L, C y, M c) \times(P m, H, S b)$

\begin{tabular}{|c|c|c|c|c|c|c|}
\hline$d^{t}$ & $C y L$ & $C y$ & $M c$ & + & Total & No. of mates \\
\hline $\begin{array}{lll}S b & \cdot & \cdot \\
P m & \cdot & \cdot \\
H & \cdot & \cdot \\
+ & \cdot & \cdot\end{array}$ & $\begin{array}{r}13 \\
10 \\
7 \\
60\end{array}$ & $\begin{array}{r}0 \\
12 \\
29 \\
38\end{array}$ & $\begin{array}{r}0 \\
15 \\
0 \\
40\end{array}$ & $\begin{array}{r}\mathrm{r} 6 \\
68 \\
4 \mathrm{I} \\
\mathrm{r} \\
\mathrm{r}\end{array}$ & $\begin{array}{r}29 \\
105 \\
77 \\
248\end{array}$ & $\begin{array}{l}1 \\
3 \\
2 \\
\cdots\end{array}$ \\
\hline $\begin{array}{l}\text { Total } \\
\text { No. of mates }\end{array}$ & $\begin{array}{r}90 \\
3\end{array}$ & $\begin{array}{r}79 \\
2\end{array}$ & $\begin{array}{r}55 \\
I\end{array}$ & $\begin{array}{r}235 \\
\ldots\end{array}$ & $\begin{array}{l}459 \\
\ldots\end{array}$ & $\ldots$ \\
\hline
\end{tabular}

Out of 459 flies emerging in one bottle, all but tro carry markers, and 86 carry two markers. The mean squares for fertility of the six flies are based on the totals in heavy type.

\section{RESULTS}

As explained above, the intensity of selection is measured as the variability of fertility which is expressed as the mean square. The

TABLE 5

Overall mean squares for the two sexes compared for each series of matings

\begin{tabular}{|c|c|c|c|c|c|c|c|}
\hline \multirow{2}{*}{ Series } & \multirow{2}{*}{ Mating } & \multicolumn{2}{|c|}{ Males } & \multicolumn{2}{|c|}{ Females } & \multirow{2}{*}{$\begin{array}{c}\text { Variance } \\
\text { ratio }\end{array}$} & \multirow{2}{*}{ Probability } \\
\hline & & Mean square & d.f. & Mean square & d.f. & & \\
\hline I & $\mathrm{C} \times \mathrm{D}$ & $1377 \cdot 8$ & 19 & $474 \cdot 9$ & 19 & $2 \cdot 90$ & ** \\
\hline 2 & $\mathrm{C} \times \overline{\mathrm{D}}$ & $734 \cdot 6$ & 44 & 183.9 & 44 & 3.99 & **** \\
\hline 3 & $\mathbf{B} \times \mathbf{A}$ & $2433^{\circ} 0$ & 26 & $858 \cdot 5$ & 26 & $2 \cdot 83$ & *** \\
\hline 4 & $A \times B$ & 463.7 & 23 & 215.0 & 23 & $2 \cdot 16$ & * \\
\hline & $\mathrm{B} \times \mathrm{A}$ & 1367.7 & 26 & $454 \cdot 5$ & 26 & $3 \cdot 01$ & ** \\
\hline 5 & $A \times B$ & $1604^{\circ} 4$ & II & $984 \cdot 6$ & II & $1 \cdot 63$ & $\ddot{*} *$ \\
\hline & $\mathrm{B} \times \mathrm{A}$ & $1700 \cdot 4$ & II & $208 \cdot 9$ & II & $8 \cdot 14$ & *** \\
\hline 6 & $\mathrm{~A} \times \mathrm{B}$ & $2798 \cdot 4$ & 23 & $992 \cdot 7$ & 23 & $2 \cdot 82$ & ** \\
\hline & $B \times A$ & $1098 \cdot 0$ & 23 & $276 \cdot 7$ & 23 & $3 \cdot 97$ & *** \\
\hline
\end{tabular}

Probability $*=.05$ or less. $\quad * *=.01$ or less. $\quad * * *=\cdot 001$ or less.

mean squares showing the gross variability between flies of the same sex in each series are shown in table 5 . In every case, including 
those where reciprocal matings were used, the mean square for males is greater than that for females. The variance ratios between the two sexes vary from $I \cdot 6$ to $8 \cdot \mathrm{I}$ and in most cases are highly significant. In series I-3 it might be argued that the stocks used for males were more variable in their effect on fertility than those chosen for females. In all other series, where reciprocal matings were made, that possibility has been eliminated.

A second possibility is that the fertility of males is more sensitive to environmental effects such as age. This can be tested in series I and 3. In series I, the ages of flies in a bottle varied at random. In males the mean square due to age is 20.5 whilst in females it is $4^{24} \cdot 6$. There is a probability of 5 per cent. that this difference is random. Thus if there is any sex difference here, it is the females which are the more sensitive to age. In series 3 the variation between bottles is analysable into that due to age of males, age of females and error variation. Age is without effect in both sexes.

A third possibility is that males are inherently more sensitive to changes in genotype. The best test of this is the variation in fertility

TABLE 6

Analysis of variance showing mean squares for effect of marker and error

\begin{tabular}{|c|c|c|c|c|c|c|c|c|c|c|c|c|}
\hline \multirow{2}{*}{ Series } & \multirow{2}{*}{ Mating } & \multirow{2}{*}{ Sex } & \multicolumn{2}{|c|}{ Marker } & \multicolumn{2}{|c|}{ Error } & \multicolumn{6}{|c|}{ Variance ratios } \\
\hline & & & M.S. & d.f. & M.S. & d.f. & $\frac{\text { Marker }}{\text { Error }}$ & P. & $\begin{array}{c}\text { Marker } \\
\delta / \$\end{array}$ & P. & $\begin{array}{c}\text { Error } \\
\delta / 9\end{array}$ & P. \\
\hline I & $\mathrm{C} \times \mathrm{D}$ & 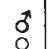 & $2537 \cdot 6$ & 4 & $1180 \cdot 9$ & 12 & $2 \cdot 15$ & $\cdots$ & 3.02 & $\ldots$ & 3.48 & * \\
\hline \multirow[t]{2}{*}{2} & $\mathrm{C} \times \mathrm{D}$ & $\begin{array}{l}0 \\
0 \\
0\end{array}$ & $\begin{array}{r}838.9 \\
2919.5\end{array}$ & 7 & $\begin{array}{l}339.5 \\
424.9\end{array}$ & & $\begin{array}{l}2.47 \\
6.87\end{array}$ & **** & & . & & \\
\hline & & 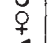 & 523.6 & $\mathrm{~T}$ & 113.1 & 24 & $4 \cdot 63$ & $* *$ & $5 \cdot 5^{8}$ & * & $3 \cdot 76$ & $* * *$ \\
\hline 3 & $\mathbf{B} \times \mathbf{A}$ & $\begin{array}{l}0 \\
0 \\
0\end{array}$ & $\begin{array}{r}754.4 \\
r 841.8\end{array}$ & 2 & $\begin{array}{r}2317.8 \\
558.6\end{array}$ & 12\{ & $\begin{array}{l}0.33 \\
3.30\end{array}$ & * & $0.4^{1}$ & $\cdots$ & $|4 \cdot 15|$ & ** \\
\hline \multirow[t]{2}{*}{4} & $\mathrm{~A} \times \mathrm{B}$ & $\begin{array}{l}0 \\
0 \\
0\end{array}$ & $\begin{array}{l}1545^{\prime} \mathrm{I} \\
2011^{7}\end{array}$ & 2\{ & $\begin{array}{r}501 \cdot 9 \\
71 \cdot 2\end{array}$ & 10 & $\begin{array}{r}3.08 \\
28 \cdot 25\end{array}$ & $* * *$ & 0.77 & $\cdots$ & $7 \cdot 05$ & **** \\
\hline & $\mathbf{B} \times \mathbf{A}$ & $\begin{array}{l}0 \\
0 \\
+\end{array}$ & $\begin{array}{r}4080 \cdot 2 \\
836 \cdot 2\end{array}$ & 2 & $\begin{array}{r}1564.7 \\
294.6\end{array}$ & 12\{ & $\begin{array}{l}2.61 \\
2.84\end{array}$ & $\ldots$ & $4 \cdot 88$ & $\cdots$ & $5 \cdot 31$ & ** \\
\hline \multirow[t]{3}{*}{5} & $A \times B$ & $\begin{array}{l}0 \\
0\end{array}$ & $2453 \cdot 2$ & 2 & $1976 \cdot 9$ & 6 & $\begin{array}{r}1.24 \\
\end{array}$ & $\dddot{* *}$ & 0.55 & $\cdots$ & $|9 \cdot 28|$ & ** \\
\hline & $\mathbf{B} \times \mathbf{A}$ & $\begin{array}{l}+ \\
0 \\
0\end{array}$ & 3273.5 & 2 & $\begin{array}{r}2930.5 \\
\end{array}$ & 6 & $\begin{array}{r}2.93 \\
1.70\end{array}$ & $\ldots$ & $7 \cdot 52$ & $\ldots$ & $29 \cdot 25$ & $* * *$ \\
\hline & $A \times B$ & $\begin{array}{l}7 \\
0 \\
0\end{array}$ & $\begin{array}{r}435 \cdot 2 \\
5254 \cdot 1\end{array}$ & 2 & $\begin{array}{r}66 \cdot 0 \\
3700 \cdot 7\end{array}$ & . & $\begin{array}{l}6.59 \\
1.42\end{array}$ & 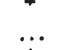 & ( J & 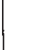 & $1-2-4$ & 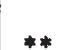 \\
\hline \multirow{2}{*}{6} & & $\begin{array}{c}1 \\
1 \\
1\end{array}$ & $4200 \cdot 8$ & & $836 \cdot 0$ & 4 & $5 \cdot 02$ & $*$ & $1-3$ & $\cdots$ & 443 & 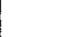 \\
\hline & & 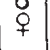 & $\begin{array}{l}340.0 \\
528 \cdot 6\end{array}$ & 2 & $\begin{array}{r}339: 6 \\
6\end{array}$ & 14 & $\begin{array}{l}0.21 \\
1 \cdot 56\end{array}$ & $\cdots$ & 0.66 & $\ldots$ & 4.94 & ** \\
\hline \multirow{2}{*}{\multicolumn{2}{|c|}{$\begin{array}{l}\text { Weighted } \\
\text { Mean }\end{array}$}} & 0 & $2602 \cdot 1$ & 22 & I $568 \cdot 8$ & 112 & 1.66 & $*$ & $\cdot 68$ & $\ldots$ & $4 \cdot 88$ & $* * *$ \\
\hline & & q & I 548 & 22 & $321 \cdot 6$ & 112 & $4 \cdot 82$ & **** & 100 & & & \\
\hline
\end{tabular}

Probability ${ }^{*}=\cdot 05$ or less.

$* *=\cdot 01$ or less.

${ }^{* * *}=\cdot$ oor or less.

between marker genes as measured by the mean square. Table 6 shows the analysis of variance of all the data into the mean squares 
due to markers and to error. The error mean square represents that variation between individuals which remains after the variation due to all analysable causes (i.e. marker, age, and overall variation between bottles) has been extracted.

The mean square for markers is not consistently higher for males than for females. The comparison can be made, where there are reciprocal matings, either between sexes with the same genotypes or between sexes in the same mating. The results are the same whichever way the comparison is made. The significance of the female marker mean squares is actually much the greater because the corresponding error mean squares by which they are judged are always the smaller. One can at least conclude that the males are not sufficiently sensitive to genotypic changes to account for the sex difference in variance of fertility.

It should be noted that the parents of the first three series were from mass cultures, whereas in later series they were either inbreds or first crosses between inbreds. If genes other than the markers were having an important influence on male fertility the error mean squares in the first three series should be higher than in the second three. This is not apparent.

The wide variation between series in their error mean squares is not surprising since there is variation in the markers used, the age of the parents, their pedigree, and the laying conditions. The overall picture is quite definite, however. In every series the error mean square is higher in the male than in the female, whether the comparison is made between flies with the same markers or from the same mating. Every variance ratio is greater than the level required for the 5 per cent. level of significance, in most series much greater.

The results can be summarised by pooling all the mean square data in table 6 . The sums of squares in each category are summed and divided by the total number of degrees of freedom. The mean squares so obtained are at the foot of the table. Though they are produced by combining heterogeneous data they can be seen to agree with the general trend. If the pooled marker mean squares are compared with their errors the males are at the 5 per cent. level of significance and in the females the ratio is much more significant. The ratio between error mean squares for the two sexes is highly significant, the males having the higher value. The ratio between marker mean squares would indicate that, if anything, the males are more sensitive to differences between marker genes. This greater sensitivity, however, is quite insufficient to account for the overall sex difference in mean squares, and in any case is not statistically significant.

It has now been demonstrated that the sex difference in variance of fertility is not due to the greater sensitivity of males to classifiable changes, environmental or genetic. The clue to this sex difference must be sought in the mechanism of sexual reproduction itself. 
Further detailed examination of the results showed that whereas only 4 per cent. of the females were unrepresented in the progeny, 2 I per cent. of the males were unrepresented (bottles in which any parent had died during the laying period were discarded). Since the males as a whole must mate as frequently as the females, if many males fail to mate there must be a similar number who mate excessively. Statistically speaking, the variance in number of mates is higher in males than in females. Table 7 shows the distribution of mates per

TABLE 7

The distribution of number of mates per fly in the two sexes

\begin{tabular}{|c|c|c|c|c|c|c|c|c|c|c|}
\hline \multirow{2}{*}{ Series } & \multirow{2}{*}{ Mating } & \multirow{2}{*}{ Sex } & \multicolumn{6}{|c|}{ No. of mates per fly } & \multirow{2}{*}{ Mean } & \multirow{2}{*}{ Mean square } \\
\hline & & & 0 & I & 2 & 3 & 4 & 5 & & \\
\hline \multirow{2}{*}{1} & $\mathrm{C} \times \mathrm{D}$ & t & 6 & 5 & 5 & 3 & 1 & $\cdots$ & \multirow[b]{2}{*}{$1 \cdot 4$} & 1.51 \\
\hline & & q & 1 & 10 & 9 & $\cdots$ & $\cdots$ & $\cdots$ & & $0 \cdot 36$ \\
\hline 2 & $\mathrm{C} \times \mathrm{D}$ & $\begin{array}{l}0 \\
0 \\
0\end{array}$ & I3 & $\begin{array}{r}8 \\
22\end{array}$ & $\begin{array}{l}13 \\
19\end{array}$ & $\begin{array}{l}9 \\
3\end{array}$ & $\begin{array}{l}2 \\
\ldots\end{array}$ & $\ldots$ & $1 \cdot 5$ & $\begin{array}{l}1 \cdot 4^{8} \\
0.44\end{array}$ \\
\hline \multirow{2}{*}{3} & $\mathbf{B} \times \mathbf{A}$ & 0 & 6 & 4 & II & 6 & ... & $\ldots$ & \multirow{2}{*}{$1 \cdot 6$} & $1 \cdot 17$ \\
\hline & & + & 1 & 11 & 12 & 3 & $\cdots$ & $\cdots$ & & 0.55 \\
\hline \multirow[t]{2}{*}{4} & $\mathbf{A} \times \mathbf{B}$ & $\begin{array}{l}0 \\
0 \\
0\end{array}$ & $\begin{array}{l}5 \\
1\end{array}$ & 13 & 6 & $\cdots$ & $\cdots$ & $\cdots$ & $i \cdot 0$ & $\begin{array}{l}0.48 \\
0.13\end{array}$ \\
\hline & $\mathbf{B} \times \mathbf{A}$ & t & 10 & 8 & 8 & 1 & $\ldots$ & $\ldots$ & \multirow{2}{*}{$1 \cdot 0$} & 0.85 \\
\hline \multirow{3}{*}{5} & & +9 & 3 & 21 & 3 & $\cdots$ & $\cdots$ & $\cdots$ & & 0.23 \\
\hline & $A \times B$ & $\begin{array}{l}0 \\
0 \\
9\end{array}$ & $\begin{array}{l}\cdots \\
\cdots\end{array}$ & $\begin{array}{l}7 \\
6\end{array}$ & $\begin{array}{l}4 \\
6\end{array}$ & $\begin{array}{l}1 \\
\ldots\end{array}$ & $\begin{array}{l}\cdots \\
\cdots\end{array}$ & $\begin{array}{l}\cdots \\
\ldots\end{array}$ & $1 \cdot 5$ & $\begin{array}{l}0.45 \\
0.27\end{array}$ \\
\hline & $\mathbf{B} \times \mathbf{A}$ & $\begin{array}{l}\pi \\
0 \\
0\end{array}$ & $\begin{array}{c}1 \\
\ldots\end{array}$ & 4 & 4 & $\begin{array}{l}3 \\
I\end{array}$ & $\cdots$ & $\ldots$ & $1 \cdot 75$ & $\begin{array}{l}0.93 \\
0.39\end{array}$ \\
\hline \multirow[t]{3}{*}{6} & $A \times B$ & $0^{7}$ & 4 & II & 4 & 5 & $\cdots$ & $\ldots$ & $1 \cdot 4$ & 0.96 \\
\hline & & t & I & 12 & 11 & $\cdots$ & $\cdots$ & $\cdots$ & & 0.27 \\
\hline & $\mathbf{B} \times \mathbf{A}$ & o & $\begin{array}{l}\cdots \\
\cdots\end{array}$ & $\begin{array}{l}8 \\
6\end{array}$ & $\begin{array}{l}11 \\
\text { I5 }\end{array}$ & $\begin{array}{l}5 \\
3\end{array}$ & $\begin{array}{l}\cdots \\
\cdots\end{array}$ & $\cdots$ & $\mathbf{I} \cdot 9$ & $\begin{array}{l}0.55 \\
0.38\end{array}$ \\
\hline
\end{tabular}

fly in the six series, together with the mean squares for number of mates. This discloses an obvious clue to the high variance in fertility of males. One has only to assume that there is a relation between the number of mates of an individual and its fertility. These results can also be expressed in terms of sexual selection. There is greater competition for mates between males than between females, which confirms that the sex difference in selection intensity is due to intramasculine selection. The pressure of this competition results in a high variability in number of matings. This intra-masculine competition is in fact that which was recognised in the introduction as the true secondary difference through which all so-called secondary sex differences are derived.

There is yet a further cause of the sex difference in fertility variance, which can be recognised if the mean fertility according to number of mates is estimated. These figures are given in table 8. It will now be observed that the fertility of the males increases steadily with the number of mates. There is a much weaker correlation 
between fertility of females and number of mates, especially if we exclude those which have not mated at all. To facilitate comparison the fertilities have been expressed as a proportion of that obtaining with a single mate. The data can then be combined without a bias being introduced owing to the differential fertility of the separate series. In combining the ratios they are weighted according to the factor $\frac{n_{1} n_{2}}{n_{1}+n_{2}}$, where $n_{1}$ and $n_{2}$ are the number of observations on which the numerator and denominator of the ratio are based. This

TABLE 8

The variation in fertility with the number of mates other than none

\begin{tabular}{|c|c|c|c|c|c|c|c|c|}
\hline \multirow{2}{*}{ Series } & \multirow{2}{*}{ Mating } & \multicolumn{4}{|c|}{$\begin{array}{c}\text { Males } \\
\text { (number of mates) }\end{array}$} & \multicolumn{3}{|c|}{$\begin{array}{c}\text { Females } \\
\text { (number of mates) }\end{array}$} \\
\hline & & 1 & 2 & 3 & 4 & $I$ & 2 & 3 \\
\hline $\begin{array}{l}1 \\
2 \\
3 \\
4\end{array}$ & $\begin{array}{l}\mathrm{C} \times \mathrm{D} \\
\mathrm{C} \times \mathrm{D} \\
\mathbf{B} \times \mathbf{A} \\
\mathrm{A} \times \mathbf{B} \\
\mathbf{B} \times \mathbf{A} \\
\mathrm{A} \times \mathbf{B} \\
\mathbf{B} \times \mathbf{A} \\
\mathrm{A} \times \mathbf{B} \\
\mathbf{B} \times \mathbf{A}\end{array}$ & $\begin{array}{r}28 \cdot 2 \\
x \cdot 0 \\
16 \cdot 3 \\
1 \cdot 0 \\
19 \cdot 8 \\
1 \cdot 0 \\
32 \cdot 7 \\
1 \cdot 0 \\
35 \cdot 4 \\
1 \cdot 0 \\
48 \cdot 0 \\
1 \cdot 0 \\
47 \cdot 8 \\
1 \cdot 0 \\
49 \cdot 5 \\
1 \cdot 0 \\
35 \cdot 6 \\
1 \cdot 0\end{array}$ & $\begin{array}{c}38 \cdot 4 \\
x \cdot 36 \\
16 \cdot 8 \\
1 \cdot 03 \\
69 \cdot 7 \\
3 \cdot 5^{2} \\
46 \cdot 0 \\
1 \cdot 41 \\
70 \cdot 0 \\
1 \cdot 98 \\
81 \cdot 0 \\
1 \cdot 69 \\
70 \cdot 5 \\
1 \cdot 47 \\
93 \cdot 3 \\
1.88 \\
72 \cdot 0 \\
2 \cdot 02\end{array}$ & $\begin{array}{r}85 \cdot 3 \\
3.02 \\
63.7 \\
3 \cdot 91 \\
97 \cdot 2 \\
4.91 \\
\ldots \\
\ldots . \\
81 \cdot 0 \\
2 \cdot 29 \\
168 \cdot 0 \\
3.50 \\
124 \cdot 0 \\
2.59 \\
130.8 \\
2.64 \\
111 \cdot 2 \\
3.12\end{array}$ & $\begin{array}{c}84 \cdot 0 \\
\mathbf{2} \cdot 98 \\
55 \cdot 0 \\
3 \cdot 37 \\
\ldots \\
\ldots \\
\ldots \\
\ldots \\
\ldots \\
\ldots \\
\ldots \\
\ldots \\
\ldots \\
\ldots \\
\ldots \\
\ldots \\
\ldots \\
\ldots\end{array}$ & $\begin{array}{r}26 \cdot 7 \\
x \cdot 0 \\
16 \cdot 8 \\
1 \cdot 0 \\
41 \cdot 3 \\
x \cdot 0 \\
27 \cdot 8 \\
1 \cdot 0 \\
40 \cdot 0 \\
1 \cdot 0 \\
58 \cdot 5 \\
1 \cdot 0 \\
69 \cdot 0 \\
1 \cdot 0 \\
79 \cdot 5 \\
1.0 \\
69 \cdot 8 \\
x \cdot 0\end{array}$ & $\begin{array}{c}39 \cdot 2 \\
x \cdot 47 \\
24 \cdot 2 \\
x \cdot 44 \\
62 \cdot 1 \\
x \cdot 50 \\
38 \cdot 5 \\
1 \cdot 38 \\
45 \cdot 7 \\
I \cdot 14 \\
71 \cdot 3 \\
x \cdot 22 \\
64 \cdot 7 \\
0 \cdot 94 \\
66 \cdot 3 \\
0 \cdot 83 \\
61.8 \\
0.89 \\
0.89\end{array}$ & $\begin{array}{c}\ldots \\
\ldots \\
41 \cdot 0 \\
2 \cdot 44 \\
77 \cdot 0 \\
x \cdot 86 \\
\ldots \\
\ldots \\
\ldots \\
\ldots \\
\ldots \\
\ldots \\
75 \cdot 0 \\
1 \cdot 09 \\
\ldots \\
\ldots \\
78 \cdot 7 \\
1 \cdot 13\end{array}$ \\
\hline \multicolumn{2}{|c|}{$\begin{array}{l}\text { Combining all data . } \\
\text { Combining series } 1-4 \\
\text { Combining series } 5 \text { and } 6\end{array}$} & $\begin{aligned} I \cdot 0 \\
I \cdot 0 \\
45 \cdot 2 \\
I \cdot 0\end{aligned}$ & $\begin{array}{r}x \cdot 79 \\
\times \cdot 76 \\
77 \cdot 0 \\
\times \cdot 70\end{array}$ & $\begin{array}{r}3 \cdot 36 \\
3 \cdot 83 \\
125 \cdot 0 \\
2 \cdot 77\end{array}$ & $\begin{array}{l}3 \cdot 24 \\
3 \cdot 24 \\
\cdots \\
\cdots\end{array}$ & $\begin{aligned} \mathbf{r} & \cdot 0 \\
\mathbf{1} & \cdot 0 \\
71 & \cdot 4 \\
1 & \cdot 0\end{aligned}$ & $\begin{array}{r}x \cdot 24 \\
x \cdot 42 \\
65 \cdot 1 \\
0.9 x\end{array}$ & $\begin{array}{r}x \cdot 79 \\
2 \cdot 17 \\
77 \cdot 8 \\
x \cdot 09\end{array}$ \\
\hline
\end{tabular}

The upper figures for each mating are the mean fertilities. The lower figures are these means expressed as ratios to the fertility with a single mate. All the data are combined together by means of their ratios. Series 5 and 6 are also combined together by means of their mean fertilities which are then converted to ratios.

is the standard method of weighting ratios. In this way the mean relative fertilities, at the foot of the table, are obtained. It appeared, however, that series 5 and 6 differed somewhat from the rest. Series I-4 were therefore combined in the manner described above giving results also shown at the foot of the table. They are also shown graphically in fig. I $(a)$. There is an obvious sex difference, the females not responding so markedly to increases above one in number of mates. 
The difference is even more noticeable, however, in series 5 and 6 . These are more comparable with one another than with the other series since they both involved the use of parents which were $F_{1}$ 's between inbred lines. The fertilities of the two series are also very similar, so that the fertilities themselves have been combined subject only to weighting according to the number of observations on which each is based. The ratios obtained from these combined fertilities are shown in table 8 and in fig. I $(b)$. The males show direct proportionality between number of mates and fertility (as before). The females, provided they have been mated with at least once, show absolutely no effect of number of mates.

That the sex difference is more obvious in these series than in the rest, may be due to the reduced vigour of the latter. If the stock

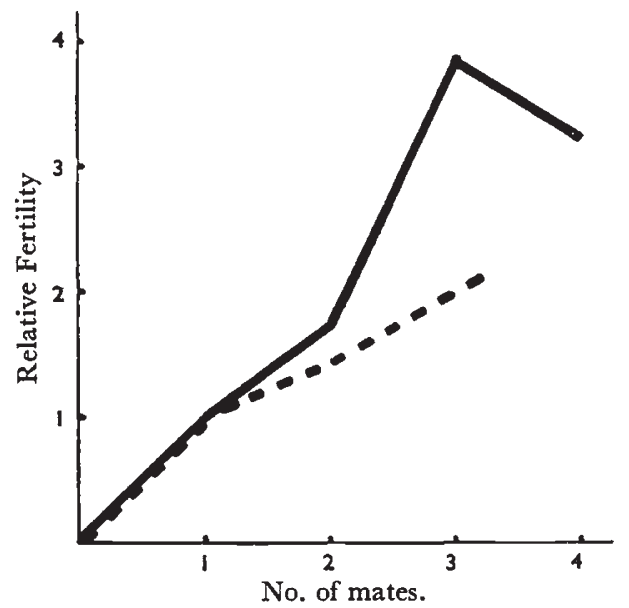

(a) Series $\mathrm{I}-4$ combined.

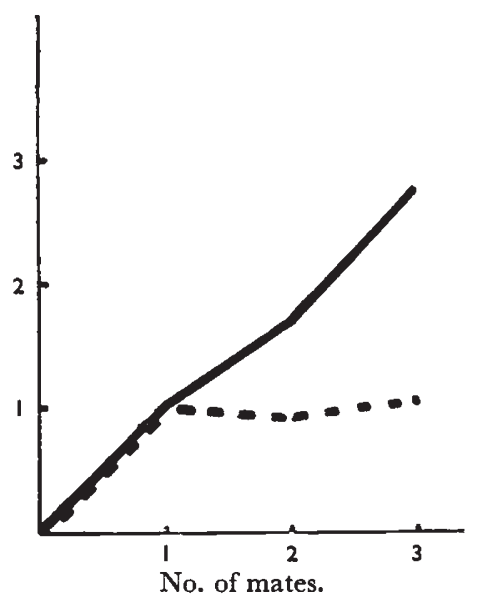

(b) Series 5 and 6 combined.

Fig. 1.-The relation between number of nates and fertility relative to that with one mate. Solid line, males : Broken line, females.

is weak, mating is less likely to occur immediately on introducing the sexes. There would then be a correlation between number of matings and earliness of the first mating which would itself be related to the fertility of the females. Again in a weaker stock, the sperm transferred per insemination may be insufficient to ensure full fertility over the 3 or 4 days of the experiment. This also would produce a correlation in females between number of mates and fertility.

It can now be seen that the sex difference in variance of fertility, which is itself a sign of intra-masculine selection, is due to the effect of number of mates per fly on fertility. This takes effect in two ways :-

(a) The higher variance, in males, of the number of mates per fly. This is a sign of intra-masculine selection.

(b) The stronger correlation, in males, between number of mates and fertility. This is the cause of intra-masculine selection.

To test whether these two factors offer a complete explanation of the sex difference, the sum of squares due to the effect of number of 
mates can be subtracted from the total sum of squares in each series. If there are no other causes of the sex difference in variance, the remainder mean squares of the two sexes will be the same. This analysis is shown in table 9 . There is a slight tendency for the male

TABLE 9

Variance of fertility analysed into that due to number of mates and the remainder

\begin{tabular}{|c|c|c|c|c|c|c|c|c|c|c|c|c|}
\hline \multirow{2}{*}{ Series } & \multirow{2}{*}{ Mating } & \multirow{2}{*}{ Sex } & \multicolumn{2}{|c|}{$\begin{array}{l}\text { Number of } \\
\text { mates }\end{array}$} & \multicolumn{2}{|c|}{ Remainder } & \multicolumn{6}{|c|}{ Variance ratios } \\
\hline & & & M.S. & d.f. & M.S. & d.f. & $\frac{\text { Mates }}{\text { Remainder }}$ & P. & $\begin{array}{c}\text { Mates } \\
\delta / \varnothing\end{array}$ & P. & $\begin{array}{c}\text { Remainder } \\
\delta / 7\end{array}$ & P. \\
\hline I & $\mathrm{C} \times \mathrm{D}$ & $\begin{array}{l}1 \\
0 \\
0\end{array}$ & $\begin{array}{r}4401 \cdot 0 \\
877 \cdot 2\end{array}$ & 4 & $571 \cdot 6$ & I 5 & $7 \cdot 70$ & $* * *$ & $5^{\circ} 02$ & $\cdots$ & I $\cdot 34$ & $\cdots$ \\
\hline \multirow[t]{2}{*}{2} & $\mathrm{C} \times \mathrm{D}$ & $\begin{array}{l}7 \\
7 \\
0 \\
0\end{array}$ & $609 \mathrm{I} \cdot \mathrm{I}$ & 4 & $\begin{array}{l}427 \cdot 0 \\
199 \cdot 0\end{array}$ & $4^{17}$ & $\begin{array}{r}2 \cdot 05 \\
30 \cdot 61\end{array}$ & $\ddot{* * *}$ & $8 \cdot 22$ & * & $1 \cdot 39$ & \\
\hline & $\mathbf{B} \times \mathbf{A}$ & $\begin{array}{l}9 \\
+ \\
0\end{array}$ & $\begin{array}{r}740 \cdot 9 \\
12019 \cdot 4\end{array}$ & $\begin{array}{l}3 \\
3\end{array}$ & $\begin{array}{r}143 \cdot 1 \\
1182 \cdot 6\end{array}$ & $\begin{array}{l}41 \\
23\end{array}$ & $\begin{array}{r}5 \cdot 18 \\
10 \cdot 16\end{array}$ & *** & & & 20 & $\cdots$ \\
\hline 3 & & o & $234^{6} \cdot 6$ & 3 & $664 \cdot 4$ & 23 & $3 \cdot 53$ & $*$ & $5 \cdot 12$ & $\cdots$ & $I \cdot 78$ & $\cdots$ \\
\hline \multirow[t]{3}{*}{4} & $\mathbf{A} \times \mathbf{B}$ & $\begin{array}{l}\pi \\
0 \\
0\end{array}$ & $\begin{array}{r}3057 \cdot 6 \\
499 \cdot 0\end{array}$ & $\begin{array}{l}2 \\
2\end{array}$ & $\begin{array}{l}216 \cdot 6 \\
187 \cdot 9\end{array}$ & 21 & $\begin{array}{r}14.12 \\
2.66\end{array}$ & $* * *$ & $6 \cdot 12$ & $\cdots$ & I'I 5 & $\cdots$ \\
\hline & $\mathbf{B} \times \mathbf{A}$ & 0 & $8050 \cdot 3$ & 3 & $496 \cdot I$ & 23 & $16 \cdot 23$ & $* * *$ & & & $I \cdot 63$ & \\
\hline & & 9 & 2255.5 & 2 & $304 \cdot 4$ & 24 & $7 \cdot 4 I$ & *** & 3.57 & $\cdots$ & 1.03 & $\cdots$ \\
\hline \multirow[t]{3}{*}{5} & $\mathrm{~A} \times \mathrm{B}$ & 告 & $\begin{array}{r}6732 \cdot 0 \\
494 \cdot 1\end{array}$ & $\begin{array}{l}2 \\
1\end{array}$ & $\begin{array}{r}464 \cdot 9 \\
1033^{\circ} 7\end{array}$ & $\begin{array}{r}9 \\
10\end{array}$ & $\begin{array}{r}14 \cdot 48 \\
0 \cdot 48\end{array}$ & $\begin{array}{c}* * * \\
\ldots\end{array}$ & $13 \cdot 62$ & $\cdots$ & 0.45 & $\cdots$ \\
\hline & $\mathbf{B} \times \mathbf{A}$ & $\delta^{*}$ & $5209 \cdot \mathrm{I}$ & 3 & $3^{8} 4 \cdot 7$ & 8 & $13 \cdot 54$ & $* * *$ & $89 \cdot 35$ & ** & $I \cdot 59$ & \\
\hline & & 9 & $58 \cdot 3$ & 2 & $242 \cdot 4$ & 9 & 0.24 & * & 0935 & & 139 & $\cdots$ \\
\hline \multirow[t]{2}{*}{6} & $A \times B$ & $\mid \begin{array}{l}0 \\
0 \\
0\end{array}$ & $\begin{array}{r}14787 \cdot 3 \\
3067 \cdot 7\end{array}$ & $\begin{array}{l}3 \\
2\end{array}$ & $\begin{array}{r}1000 \cdot 1 \\
795 \cdot I\end{array}$ & $\begin{array}{l}20 \\
21\end{array}$ & $\begin{array}{r}14 \cdot 79 \\
3 \cdot 86\end{array}$ & $\begin{array}{l}* * * \\
*\end{array}$ & $4 \cdot 82$ & $\cdots$ & $1 \cdot 26$ & $\cdots$ \\
\hline & $\mathbf{B} \times \mathbf{A}$ & $\delta_{0}^{2}$ & $8946 \cdot 2$ & 2 & $350 \cdot 6$ & $2 \mathrm{I}$ & $25 \cdot 52$ & $* * *$ & $21 \cdot 45$ & * & $1 \cdot 33$ & .. \\
\hline \multirow{2}{*}{\multicolumn{2}{|c|}{ Combined }} & "ే & $7678 \cdot 4$ & 26 & $524 \cdot 0$ & 180 & $14 \cdot 65$ & $\begin{array}{l}* * * \\
* * *\end{array}$ & $6 \cdot 05$ & $* * *$ & $\mathrm{I} \cdot 32$ & $*$ \\
\hline & & 7 & I $268 \cdot 8$ & I 9 & $397^{\circ} 9$ & 187 & $3 \cdot 19$ & $* * *$ & & & & \\
\hline
\end{tabular}

remainder mean squares to be the higher, but this is never significant. Variance in number of mates is, therefore, the only important cause of the sex difference in variance of fertility.

\section{DISCUSSION}

It has been demonstrated that in Drosophila melanogaster sexual selection is much more effective in males than in females. This phenomenon is likely to occur also in other species of Drosophila. It might be expected to produce a situation in which males were less discriminating in their mating behaviour than females. This situation would mean that sexual isolation as demonstrated in Drosophila species by Dobzhansky and his co-workers, would be determined by discrimination on the part of the females rather than on that of the males.

The standard practice, however, of enclosing males of one kind 
with females of two kinds, gives the latter no choice. It will disclose differences between strains of female only in the resistance they offer to a given strain of males. This would be compounded of their ability to discern whether males were of their own strain, their general mating propensity, and their ability to repel males with which they do not wish to mate.

An apparent outbreeding tendency could then be explained by a combination of weak discrimination with a strong mating propensity in the females of strain B when enclosed with females and males of strain A. It would seem desirable to carry out mating in which females were given a choice of males. Though there would be great technical difficulties, it would be informative to obtain comparative data from both types of mating.

On the assumption that all the discrimination is exercised by the females, further information can be obtained from the data on sexual isolation. The complementary matings $\left[(\mathrm{A}+\mathrm{B})\right.$ 우우 $\times \mathrm{A} \boldsymbol{\delta}^{\top} \mathrm{\sigma}^{\mathrm{a}}$ and $(\mathrm{A}+\mathrm{B})$ 우우 $\left.\times \mathrm{B} \quad \delta^{\top} \delta^{*}\right]$ then bear a special relation to one another. The degree of sexual isolation is measured by the isolation index which varies from $+I$ to -1 . A positive index denotes a preponderance of intra-strain matings, a negative index a preponderance of inter-strain matings. The additional information is obtained from the sum of the isolation indices of complementary matings and from their difference. The sum denotes the degree of sexual isolation. The difference denotes the degree of non-specific sexual selection favouring females of one strain. Theoretically the sum could be negative though this would imply discrimination in favour of cross-breeding as distinct from the non-specific effect, which is unlikely. A study of the numerous data on the subject shows no evidence of this.

Beyond demonstrating the strength of intra-masculine selection in Drosophila melanogaster, the experiments described in the first part of this paper have also shown its cause, namely, the greater dependence of males for their fertility on frequency of insemination. Though this will clearly apply to all animals in which the female can store sperm, it can be shown that it is in fact an almost universal attribute of sexual reproduction.

In most animals the fertility of the female is limited by egg production which causes a severe strain on their nutrition. In mammals the corresponding limiting factors are uterine nutrition and milk production, which together may be termed the capacity for rearing young. In the male, however, fertility is seldom likely to be limited by sperm production but rather by the number of inseminations or the number of females available to him. In promiscuous species the share of males in the progeny of any female will be proportional to the number of inseminations for which each is responsible. In general, then, the fertility of an individual female will be much more limited than the fertility of a male.

The primary cause of intra-masculine selection would thus seem 
to be that females produce much fewer gametes than males. Consequently there is competition between male gametes for the fertilisation of the female gametes. And this competition is vastly more intense than that hitherto considered between zygotes.

The primary feature of sexual reproduction is to be sure the fusion of gametes irrespective of their relative size, but the specialisation into large immobile gametes and small mobile gametes produced in great excess (the primary sex difference), was a very early evolutionary step. One would therefore expect to find in all but a few very primitive organisms, and those in which monogamy combined with a sex ratio of unity eliminated all intra-sexual selection, that males would show greater intra-sexual selection than females. This would explain why in unisexual organisms there is nearly always a combination of an undiscriminating eagerness in the males and a discriminating passivity in the females. Even in derived monogamous species (e.g. man) this sex difference might be expected to persist as a relic.

With intra-masculine selection males will be expected to show polygamous tendencies, whereas in females there would be selection in favour of obtaining only one mate after which they would become relatively indifferent. In Drosophila it has been shown that there is a high variance in number of mates in males, implying a polygamous tendency. Regarding the other sex Rendel (I944) observed that, immediately after one mating, females of Drosophila subobscura actually repelled courting males. It would appear then that polygyny has arisen as a result of intra-masculine selection.

On the other hand, one would expect to find polyandry only when special circumstances reduced the effect of normal selective forces. If there were an excess of males polyandry would not normally improve the fertility of the species since the number of females would be the limiting factor. Polyandry could, however, sometimes have a selective value. Thus in fishes, where fertilisation is external and very inefficient the sperm of several males may be necessary to fertilise all the eggs of one female.

Intra-masculine selection will often have the effect that a character which increases the chances of its possessors mating will be of epigamic value in females but only of value in intra-sexual selection in males. This situation can be seen in moths where the female has a scent to attract males. A female with a stronger scent than the rest would be found earlier and would lay its eggs sooner, but unless there were a severe food shortage there would be no adverse effect on the progenies of other less attractive females. On the other hand, a male with a stronger sense of perception would fertilise more females than his competitors and would reduce their chances of rearing progenies.

If the differentiation into male and female gametes is the basis of intra-masculine selection there should be signs of this selection in plants as well as in animals. Since plants are usually hermaphrodite and also sedentary, such selection would only be expected to show 
in the pollen. The general tendency for the production of microspores far in excess of the minimum required to produce effective fertilisation is explicable in this way. In dioecious plants or moneocious plants where the sexes are separated the results of intra-masculine selection might be more obvious. A possible example here is the insectpollinated sallow (Salix caprea) in which the male catkins are brightly coloured whereas the female catkins are inconspicuous (though both produce nectar).

The widespread distribution of intra-masculine selection would appear to be linked to another sex difference which has not yet been explained, namely, that when sex determination is by the XY mechanism, the male is usually the heterogametic sex. In animals the $\mathrm{XY}$ mechanism has become stabilised in large groups of common origin and has therefore probably arisen only a few times. The female is heterogametic in Lepidoptera, birds and a few fishes. The male is heterogametic in all other insects and vertebrates. In plants where dioecism has arisen independently on many occasions the position is even more indicative of a selective advantage in heterogametic males. Of the several species in which the $\mathrm{X}$ and $\mathrm{Y}$ have been distinguished, only one; Fragaria elatior has a heterogametic female. On the other hand Rumex, Humulus, Mercurialis and Melandrium are only the best known examples with heterogametic males.

In the early stages of differentiation between $X$ and $Y$, the $Y$ could act as a store of genes which were of intra-masculine selective value but deleterious in females. As differentiation proceeded by disorganisation of the $\mathrm{Y}$ and before dosage compensation became complete the heterogametic sex would be at a disadvantage owing to the functioning of genes in the hemizygous condition. A still greater handicap for the heterogametic sex is that when the $Y$ is greatly disorganised and XY individuals are hemizygous for many genes the genetic balance normally obtained through the diploid condition is lost as far as the sex chromosomes are concerned. It has been shown that the loss of males can be compensated for by greater reproductive activity of the remaining males whereas the loss of females can not be made up so easily. Species with heterogametic males would therefore have an advantage over those with heterogametic females. The primary sex difference can therefore account for not only intra-masculine selection but also the sex distribution of the XY mechanism.

\section{SUMMARY}

I. The evidence on intra-sexual selection has so far indicated that it acts mainly in males, but it has given no adequate explanation why this should be so.

2. Experiments with Drosophila melanogaster using multiple matings in which each fly carries a different dominant marker, show that 
the contribution of males to the next generation is more variable than that of females.

3. This sex difference is independent of environmental and heritable effects. Males must therefore be inherently subject to stronger selection than females, which must be due to a more intense intra-sexual action.

4. The intensity of intra-masculine selection is due to the greater dependence of the fertility of males on frequency of insemination. This seems to be inherent in primary sexual differentiation in both animals and plants.

5. Undiscriminating eagerness in males and discriminating passivity in females must have been early effects of intra-masculine selection and are naturally widespread. Previous experiments on sexual isolation in Drosophila can be interpreted on the assumption that females (not males) exercise discrimination.

6. Intra-masculine selection and related effects may have influenced the evolution of animals and plants in various ways.

The author wishes to thank Dr K. Mather for his help in interpreting the results. The work was carried out under the auspices, and with the financial assistance, of the Agricultural Research Council.

\section{REFERENCES}

DARWIN, c. 1871 .

Descent of Man: Part II Sexual Selection.

DOBZHANSKY, TH. 1944 .

Experiments on sexual isolation in Drosophila. III. Geographic strains of $D$. sturtevanti.

P.N.A.S. 30,335 .

DOBZHANSKY, TH., AND KOLLER, P. C. 1938.

An experimental study of sexual isolation in Drosophila.

Biol. Zent. $5^{8}, 5^{89}$.

DUBININ, N. P. 1928.

Zh. Exp. Biol. 4, I31.

HUXIEY, J. S. $193^{8}$.

Darwin's theory of sexual selection.

Am. Nat. 72, 416.

KAUfMANN, B. P., AND DEMEREC, M. 1942.

Utilisation of sperm by the female of Drosophila melanogaster.

Am. Nat. 76, 445 .

LOBASHOV, M. E. 1939 .

C.R. Acad. Sci. U.R.S.S. 23,827 .

NACHTSHEM, $\mathrm{H} . \quad 1927$.

Der Lebensdauer genotypisch verschiedener Spermien bie Drosophila.

Verh. V int. Kong. Vererb. Z.I.A.V. Suppl. II, I I 43 (1928). 
RENDEL, J. M. I944.

Genetics and cytology of Drosophila subobscura. II. Normal and selective matings in $D$. subobscura.

7. Genet. 46,287 .

STALKER, H. D. 1942 .

Sexual isolation studies in the species complex Drosophila virilis.

Genetics 27, 238.

TAN, c. C. 1946 .

Genetics of sexual isolation between Drosophila pseudoobscura and D. persimilis.

Genetics 3I, $55^{8}$. 